\title{
Measurement of Popliteal Artery Diameter: A Cadavaric Study
}

\author{
Sanjay Singh ${ }^{1}$, Saroj Kumarr ${ }^{2}$, Md. Tabrej Alam ${ }^{3}$, Kamil Khan ${ }^{3}$ \\ ${ }^{1}$ Tutor, Department of Anatomy, Hind institute of Medical Science, Ataria, Sitapur, ${ }^{2}$ Associate Professor, Department of Anatomy, Hind institute of Medical \\ Science, Ataria, Sitapur, ${ }^{3}$ Assistant Professor, Department of Anatomy, Hind institute of Medical Science, Ataria, Sitapur.
}

\section{Abstract}

\begin{abstract}
Introduction: The popliteal artery is the branches off from the femoral artery. It is located in the knee towards the back of the legs. The clinicians and radiologists dealing with the popliteal area use description of branching pattern of the popliteal artery, in which it first gives rise to anterior tibial artery followed by the tibial peroneal trunk, which then terminates by dividing into the posterior tibial and peroneal arteries. As popliteal artery is one of the most common sites for aneurysm formation, the knowledge of the normal popliteal artery diameter is essential to determine the relevance of popliteal dilatations. Objective: Considering the clinical importance of diameter of popliteal artery, this study was undertaken to note the internal diameter of popliteal artery. Subjects and Methods: The present study was conducted on 50 specimen embedded in $10 \%$ formalin from the department of Anatomy of tertiary care hospital \& medical college. Cadavers which had gross pathological deformities in its lower limbs were excluded from the study. All the cadavers were adult males and females. Results: This study states right popliteal arteries are slightly larger $(4.9 \pm 0.7 \mathrm{~mm})$ as compare to left popliteal artery $(4.8 \pm 0.5 \mathrm{~mm})$. This study also reconfirm popliteal arteries of men are slightly larger than that of female $(4.9 \pm 0.7 \mathrm{~mm}),(4.6 \pm 0.9 \mathrm{~mm})$ and left popliteal artery $(4.8 \pm 0.5 \mathrm{~mm}),(4.6 \pm 0.7 \mathrm{~mm})$ respectively. On the other hand terminal part its diameter is slightly larger in male $(4.5 \pm 0.6 \mathrm{~mm})$ as compare to female $(4.3 \pm 0.5 \mathrm{~mm})$. This study also shows terminal end of left popliteal arteries $(3.8 \pm 0.7 \mathrm{~mm})$ are smaller than right popliteal arteries $(4.3 \pm 0.5 \mathrm{~mm})$. Conclusion: The present study was done in a small cadaveric sample. In our prospective different live and cadaveric study will be helpful for vascular surgeons, radiologists. The variation in the measurement of our study compare to other study may be due to the difference in live and cadaveric spacemen or due to the method of measurement. Therefore, we suggest before making any decision study on much larger sample should be consider.
\end{abstract}

Keywords: Popliteal arteries, femoral arteries, cadaver.

Corresponding Author: Dr. Sanjay Singh, Tutor, Department of Anatomy, Hind institute of Medical Science, Ataria, Sitapur.

Received: January 2019

Accepted: January 2019

\section{Introduction}

The popliteal artery is the branches off from the femoral artery. ${ }^{[1]}$ It is located in the knee towards the back of the legs. Its courses near the adductor canal and the adductor hiatus, distinctive open areas inside the thigh. ${ }^{[2]}$ At its far end, it splits into the anterior and posterior tibial arteries. During its course, the popliteal artery branches into other significant blood vessels. These include the sural artery and the various types of genicular arteries. ${ }^{[3]}$ As the primary distributor of oxygenated blood to regions around the knee, the artery is not the same as the popliteal vein. The two blood vessels run a similar course in close proximity. Yet, the vein drains deoxygenated blood and moves it up the leg, to the femoral vein. Ultimately, all deoxygenated blood ends up at the lungs and the heart, before it is recirculated into the arterial system. The popliteal artery is palpable (i.e. detectable by hand). People are able to find it and use it to count a pulse in the back of the knee. ${ }^{[4]}$ If the knees are slightly flexed to about 45 degrees the pulse will be easier to locate. The pulsations are best felt in the inferior part of the fossa where the popliteal artery is related to the tibia. ${ }^{[5]}$
Weakening or loss of the popliteal pulse is a sign of a femoral artery obstruction. The artery may divide into its terminal branches proximal to popliteus the anterior tibial artery sometimes descends anterior to the muscle. ${ }^{[6-8]}$ The clinicians and radiologists dealing with the popliteal area use description of branching pattern of the popliteal artery, in which it first gives rise to anterior tibial artery followed by the tibial peroneal trunk, which then terminates by dividing into the posterior tibial and peroneal arteries. ${ }^{[9]}$ As popliteal artery is one of the most common sites for aneurysm formation, the knowledge of the normal popliteal artery diameter is essential to determine the relevance of popliteal dilatations. The pulsations are best felt in the inferior part of the fossa where the popliteal artery is related to the tibia. Weakening or loss of the popliteal pulse is a sign of a femoral artery obstruction. ${ }^{[10]}$ A popliteal aneurysm (abnormal dilation of all or part of the popliteal artery) usually causes edema and pain in the popliteal fossa. ${ }^{[1]} \mathrm{A}$ popliteal aneurysm may be distinguished from other masses by palpable pulsations (thrills) and abnormal arterial sounds (bruits) detectable with a stethoscope ${ }^{[12]}$ Because the artery lies deep to the tibial nerve, an aneurysm may stretch the nerve or compress its blood supply (see vasa vasorum). Pain 
from such nerve compression is usually referred, in this case to the skin overlying the medial aspect of the calf, ankle or foot. Because the artery is closely applied to the popliteal surface of the femur and the joint capsule, fractures of the distal femur or dislocations of the knee may rupture the artery, resulting in hemorrhage. ${ }^{[13]}$ Furthermore, because of their proximity and confinement within the fossa, an injury of the artery and vein may result in an arteriovenous fistula (communication between an artery and a vein). Failure to recognize these occurrences and to act promptly may result in the loss of the leg and foot sanitation. Considering the clinical importance of diameter of popliteal artery, this study was undertaken to note the internal diameter of popliteal artery.

\section{Subjects and Methods}

The present study was conducted on 50 specimen embedded in $10 \%$ formalin from the department of Anatomy of tertiary care hospital \& medical college. Out of 50 specimens 39 specimens were from males and 11 were from female. All the cadavers belonged to Asian Indian subjects, the age and gender of which were not determined. Cadavers which had gross pathological deformities in its lower limbs were excluded from the study. Side determination was done using existing universally accepted criteria. All the cadavers were adult males and females ranging between the age group of 25-70 years. After taking incision, skin was reflected followed by removal of superficial fascia and deep fascia to expose the popliteal fossa. Hamstring muscles were reflected to expose the region of adductor hiatus i.e. origin of popliteal artery and two heads of gastrocnemius were reflected to expose the popliteal vessels. Soleus muscle was dissected vertically up to the termination of popliteal artery. Then popliteal artery was examined in each cadaver.

\section{Parameters measured}

1. Inner circumference of popliteal artery at its origin and at its termination.

At the level of adductor hiatus, intact piece of popliteal artery was removed, incised and cut opened.

\section{Result}

From this study we can state right popliteal arteries are slightly larger $(4.9 \pm 0.7 \mathrm{~mm})$ as compare to left popliteal artery $(4.8 \pm 0.5 \mathrm{~mm})$. This study also reconfirm popliteal arteries of men are slightly larger than that of female $(4.9 \pm$ $0.7 \mathrm{~mm}),(4.6 \pm 0.9 \mathrm{~mm})$ and left popliteal artery $(4.8 \pm 0.5$ $\mathrm{mm}),(4.6 \pm 0.7 \mathrm{~mm})$ respectively. [Table $1 \&$ Figure 1]

Table 1: Representing mean diameters of popliteal artery at its origin

\begin{tabular}{|l|l|l|l|}
\hline & $\begin{array}{l}\text { Total } \\
\text { specimen }\end{array}$ & $\begin{array}{l}\text { Mean diameter } \\
\text { of right popliteal } \\
\text { artery }\end{array}$ & $\begin{array}{l}\text { Mean diameter } \\
\text { of left popliteal } \\
\text { artery }\end{array}$ \\
\hline Male & 39 & $4.9 \pm 0.7 \mathrm{~mm}$ & $4.8 \pm 0.5 \mathrm{~mm}$ \\
\hline Female & 11 & $4.6 \pm 0.9 \mathrm{~mm}$ & $4.6 \pm 0.7 \mathrm{~mm}$ \\
\hline Total & 50 & - & - \\
\hline
\end{tabular}

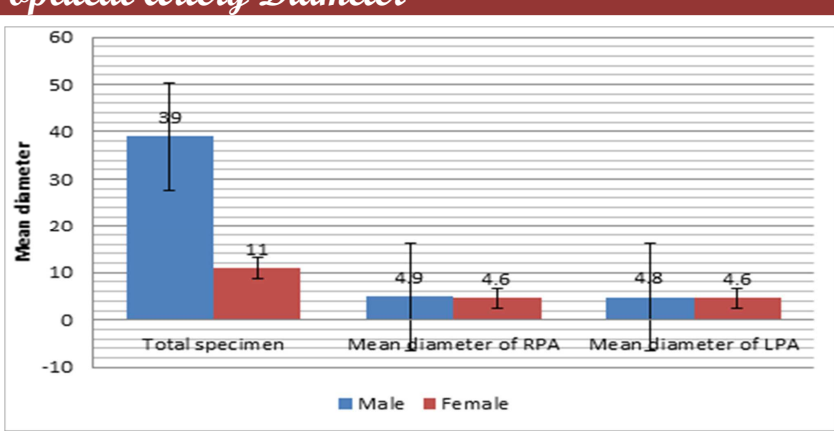

Figure 1: Representing mean diameters of popliteal artery at its origin

Table 2: Representing mean diameters of popliteal artery at it
termination.
\begin{tabular}{|l|l|l|l|}
\hline & $\begin{array}{l}\text { Total } \\
\text { specimen }\end{array}$ & $\begin{array}{l}\text { Mean diameter } \\
\text { of rean diameter of } \\
\text { popliteal artery }\end{array}$ & $\begin{array}{l}\text { Mean } \\
\text { left artery } \\
\text { aopliteal }\end{array}$ \\
\hline Male & 39 & $4.5 \pm 0.6 \mathrm{~mm}$ & $4.1 \pm 0.8 \mathrm{~mm}$ \\
\hline Female & 11 & $4.3 \pm 0.5 \mathrm{~mm}$ & $3.8 \pm 0.7 \mathrm{~mm}$ \\
\hline Total & 50 & - & - \\
\hline
\end{tabular}

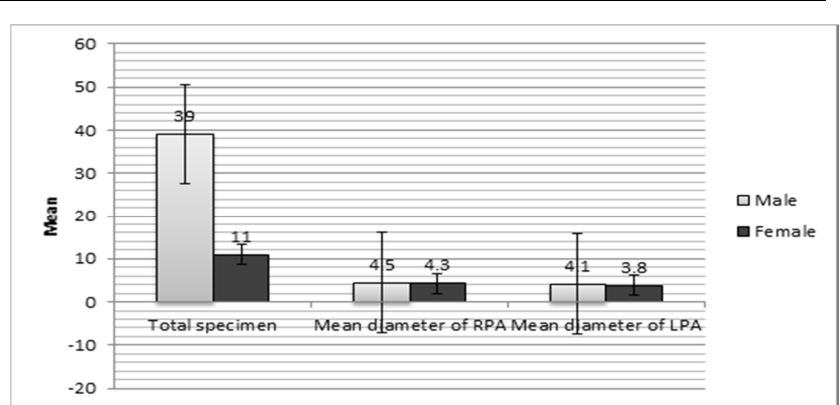

Figure 2: Representing mean diameters of popliteal artery at it termination

Similar to the origin of popliteal artery in terminal part its diameter is slightly larger in male $(4.5 \pm 0.6 \mathrm{~mm})$ as compare to female $(4.3 \pm 0.5 \mathrm{~mm})$. This study also shows terminal end of left popliteal arteries $(3.8 \pm 0.7 \mathrm{~mm})$ are smaller than right popliteal arteries $(4.3 \pm 0.5 \mathrm{~mm})$.[Table 2 \& Figure 2]

\section{Discussion}

The popliteal artery branches off from the femoral artery. It is located in the knee and the back of the leg. During its course, the popliteal artery branches into other significant blood vessels. These include the sural artery and the various types of genicular arteries. As the primary distributor of oxygenated blood to regions around the knee, the artery is not the same as the popliteal vein. The two blood vessels run a similar course in close proximity. Yet, the vein drains deoxygenated blood and moves it up the leg, to the femoral vein. Ultimately, all deoxygenated blood ends up at the lungs and the heart, before it is recirculated into the arterial system. The popliteal artery is palpable (i.e. detectable by hand). As popliteal artery is one of the most common sites for aneurysm formation, the knowledge of the normal popliteal artery diameter is essential to determine the relevance of popliteal dilatations. Considering the clinical importance of diameter of popliteal artery. Accurate anatomical knowledge of the popliteal artery and the region 
of popliteal fossa are of great importance in various diagnostic and therapeutic procedures. Knowledge of morphometric data of popliteal artery is important for infrapopliteal interventions such as bypass surgery, trans-luminal angioplasty and sub intimal angioplasty. Despite improvements in vascular surgical techniques, popliteal vascular injuries and popliteal aneurysms continue to be potentially dangerous lesions with high percentage of leg amputations. ${ }^{[14-16]}$ This study state right popliteal arteries are slightly larger $(4.9 \pm 0.7 \mathrm{~mm})$ as compare to left popliteal artery $(4.8 \pm 0.5 \mathrm{~mm})$. This study also reconfirm popliteal arteries of men are slightly larger than that of female $(4.9 \pm$ $0.7 \mathrm{~mm}),(4.6 \pm 0.9 \mathrm{~mm})$ and left popliteal artery $(4.8 \pm 0.5$ $\mathrm{mm}),(4.6 \pm 0.7 \mathrm{~mm})$ respectively. Majority of the studies on the popliteal artery had measured the diameter of the popliteal artery at various points using B-mode ultrasound and Duplex ultrasound scanning methods. There are few cadaveric studies which measured the diameter of the popliteal artery. Thomas Sandgren et al. measured the diameter of the popliteal artery in 121 healthy human volunteers (59 males and 62 females) with echo tracking Bmode ultrasonography and found that the mean diameter of the popliteal artery was $7.4 \mathrm{~mm} \pm 0.9 .^{[17]}$ They also found that the diameter of the popliteal artery was larger in males as compared to females in $>25$ year age group. ${ }^{[17]}$ This is similar to the result of our study. Similarly, Wolf YG et al. in their study on 204 (104 male and 100 female) healthy volunteers measured the external diameter of the popliteal artery at three levels using Duplex ultrasound scan. ${ }^{[18]}$ They found that the external diameter of the popliteal artery in its upper part was $6.4 \mathrm{~mm} \pm 0.7$, in middle part was $6.4 \mathrm{~mm} \pm 0.7$ and in its distal part was $4.6 \mathrm{~mm} \pm 0.6$. With the help of their findings, they concluded that the diameter of the normal popliteal artery was not uniform throughout its length this finding is similar to our study which shows terminal end of left popliteal arteries $(3.8 \pm 0.7 \mathrm{~mm})$ are smaller than right popliteal arteries $(4.3 \pm 0.5 \mathrm{~mm})$. This study was done on cadaver who was embedded in $10 \%$ formalin, whereas most of the author had carried their study on living subjects. Therefore the variation in the measurement may be due to the difference in live and cadaveric spacemen or due to the method of measurement, it is expected that there will be some difference in measurements. In the present study, the diameters of popliteal artery at origin and termination end shows difference in measurement and were smaller than those noted by previous authors. Therefore, we suggest before making any decision study on much larger sample should be consider.

\section{Conclusion}

The present study was done in a small cadaveric sample. In our prospective different live and cadaveric study will be helpful for vascular surgeons, radiologists. The variation in the measurement of our study compare to other study may be due to the difference in live and cadaveric spacemen or due to the method of measurement. Therefore, we suggest before making any decision study on much larger sample should be consider.

\section{References}

1. Kim D, Orron DE, Skillman JJ. Surgical significance of popliteal arterial variants. A unified angiographic classification. Annals of surgery. 1989 Dec;210(6):776.

2. Kachlik D, Pechacek V, Musil V, Baca V. The deep venous system of the lower extremity: new nomenclature. Phlebology. 2012 Mar;27(2):48-58.

3. Hughes CW. Arterial repair during the Korean War. Annals of Surgery. 1958 Apr;147(4):555.

4. HILL RD, SMITH III RB. 30 Examination of the Extremities: Pulses, Bruits, and Phlebitis. Clinical methods: The history, physical, and laboratory examinations. 1990:148.

5. Servello MA. Clinical syndrome of anomalous position of the popliteal artery. Circulation. $1962 \mathrm{Nov} ; 26: 885-90$.

6. Colborn GL, Lumsden AB, Taylor BS, Skandalakis JE. The Surgical Anatomy of the Popliteal Artery. Am surg. 1994 Apr;60(4):238-246.

7. Richard LM Newell. Pelvic Girdle and Lower Limb (knee).In Gray's Anatomy: The Anatomical Basis of Clinical Practice. Edited by Standring S. 39th edition. Edinburgh: Elsevier Churchill Livingstone, printed in Spain, 2005; p 1471, 1486-1487.

8. Datta AK. Essentials of Human Anatomy (Superior and inferior extremities) Part III. 3rd edition. Kolkata. Current Books International. 2007; p 195-197.

9. Day CP, Orme R. Popliteal Artery Branching Patterns. An Angiographic Study. Clin Radiol. 2006;61(8):696-699.

10. Denny-Brown D. The treatment of recurrent cerebrovascular symptoms and the question of "vasospasm". Medical Clinics of North America. 1951 Sep 1;35(5):1457-74.

11. Radonić V, Koplić S, Giunio L, Božić I, Mašković J, Buća A. Popliteal artery entrapment syndrome: diagnosis and management, with report of three cases. Texas Heart Institute Journal. 2000;27(1):3

12. Reid MR, McGuire J. Arteriovenous aneurysms. Annals of surgery. 1938 Oct;108(4):643.

13. Fanelli GC, Orcutt DR, Edson CJ. The multiple-ligament injured knee: evaluation, treatment, and results. Arthroscopy: The Journal of Arthroscopic \& Related Surgery. 2005 Apr 1;21(4):471-86.

14. Deglise S, Qanadli SD, Rizzo E, Ducrey N, Doenz F, Haller C, Denys A, Corpataux JM. Long-Term Follow-Up. Surgically Excluded Popliteal Artery Aneurysms With Multislice CT Angiography And Doppler Ultrasound. Eur Radiol 2006;16:13231330.

15. Orcutt MB, Levine BA, Root HD, Sirinek KR. The Continuing Challenge of Popliteal Vascular Injuries. Am J Surg 1983;146:758761.

16. Smith PN, Gelinas J, Thain L, Rorabeck CH, Bourne RB. Popliteal Vessels in Knee Surgery. A Magnetic Resonance Imaging Study. Clin Orthop Relat Res 1999;367:158-164.

17. Thomas Sandgren, Björn Sonesson, Asa Ryden Ahlgren, Toste Länne. Factors Predicting the Diameter of the Popliteal Artery in Healthy Humans. J Vasc Surg. Aug 1998;28(2):284-289.

18. Wolf YG, Kobzantser Z, Zelmanovich L. Size of Normal and Aneurysmal Popliteal Arteries: A Duplex Ultrasound Study. J Vasc Surg 2006;43(3):488-492. 
Copyright: ( $)$ the author(s), publisher. Academia Anatomica International is an Official Publication of "Society for Health Care \& Research Development". It is an open-access article distributed under the terms of the Creative Commons Attribution Non-Commercial License, which permits unrestricted non-commercial use, distribution, and reproduction in any medium, provided the original work is properly cited.

How to cite this article: Singh S, Kumar S, Alam MT, Khan K. Measurement of Popliteal Artery Diameter: A Cadavaric Study. Acad. Anat. Int. 2019;5(1):12-15.

DOI: dx.doi.org/10.21276/aanat.2019.5.1.4

Source of Support: Nil, Conflict of Interest: None declared. 